\title{
WEB-BASED QUESTIONNAIRES FOR TYPE THEORY COURSE
}

\author{
Daniel MIHÁLYI*, Monika PENIAŠKOVÁ*, Ján PERHÁČ* , Jurij MIHELIČ*** \\ *Department of Computers and Informatics, Faculty of Electrical Engineering and Informatics, Technical University of Košice, \\ Letná 9, 04200 Košice, Slovak Republic, Tel.: +421 55602 2527, E-mail: daniel.mihalyi@tuke.sk, \\ monika.peniaskova@student.tuke.sk,jan.perhac@tuke.sk \\ ** Laboratory for Algorithms and Data Structures, Faculty of Computer and Information Science, University of Ljubljana, \\ Večna pot 113, SI-1001 Ljubljana, Slovenia, Tel.: +386 1479 8236, E-mail: jurij.mihelic@ fri.uni-lj.si
}

\begin{abstract}
This paper describes our effort on the usage of modern information and communication technologies as well as innovation process in the field of teaching. Our goal is to design and develop a web-based system to support management and analysis of course questionnaires for students. The proposed system is broadly divided into two parts. First, we describe the system architecture followed by a preparation of a suitable network environment and a design of a database model used for storage of data about the questionnaires. Second, we present a design of the proposed website, its structure, and finally a proper layout of the questionnaires. An important functionality of our system is also to provide various statistical information obtained from the responses. This enables teachers to exercise introspection and self-reflection in order to improve quality of their teaching of the course. The main goal of our long-term effort is a deployment of the system into use within the course on Type theory, which allows students to grow their knowledge in the principles of type systems and languages of functional programming paradigm.
\end{abstract}

Keywords: database model, questionnaire survey, semantic differential, web application, web user interface

\section{INTRODUCTION}

Presently, the most important activities at numerous universities are operating on the principles of quality management in accordance with a systematic repetition of the PlanDo-Check-Act cycle [3]. The main activities at the universities are learning, research, and development as well as business activity.

The main purpose of the university is to serve the society in general. The aim of the university educational process is to ensure a gradual, continuous acquisition of knowledge and skills for its students. This is ensured by a quality, efficient, and cost-effective implementation of teaching processes by university teachers. Improvement of a learning process is preferred in order to increase student's motivation as well as improve personal and professional growth of teachers. Another important part is the improvement of material and technical provisioning in accordance with current trends in the field of teaching and a deployment of solutions based on information and communication technologies such as [21], automatic assessment in visual form [2], or automatic assessment of homework assignments [19] too.

Valuable information, which can be obtained through questionnaire surveys, could help achieving positive changes in methods of teaching and teacher's self-reflection on teaching a certain course. Students can anonymously express their individual opinions and the reasons for their attitude to the course. Based on that, a teacher can obtain information about the interest or lack thereof in the course.

There are already several works using Audience Response Systems (ARS) for electronic interaction between lecturers and audience. In [12], Jackowska et al. compare results of learning outcomes of the students taught with and without question-based learning methodology. The approach of Pietriková [17] provides a survey on utilization possibilities of ARS in various forms, with a focus on particular advantages.
Our work began with the design of the web portal from the diploma thesis [16]. The expected result of this work will be a CMS Drupal program module that is used to complete the questionnaires by students from the oficial course website at https://tt.kpi.fei.tuke.sk/. Filling them should be simple, fast, and effective, and is usually performed in the computer laboratory room.

The purpose of this work is to analyze the questionnaire surveys on the Type Theory course and based on this analysis, suggest the functionality and layout of the website. In this contribution we propose a basic structure and functionality of the website and also a physical database model that can be used while creating the database. We also analyze the methods of questionnaire evaluation. Then we propose a conceptual, logical and physical database model, which shows the possibility of implementing a database for MySQL database system [15]. Finally, we have designed web page items before and after successful user authentication.

In the next section we describe a database system used for storing questionnaire data and the corresponding data model. In Section 3 we present the design of a website, its structure, and menu system. In Section 4 we focus on questionnaires, their analysis, for which we also give a case study. Finally, we conclude the paper.

\section{APPLICATION ARCHITECTURE}

We built our Information and Communications Technologies (ICT) solution on client-server architecture based on high-quality, stable, and scalable open-source server software available via Debian GNU/Linux distribution Jessie [6]. The main reason for choosing this distribution is a precise package management system, where system tools give the administrator complete control over the packages that are already installed, including the ability to automatically update the whole operating system. 


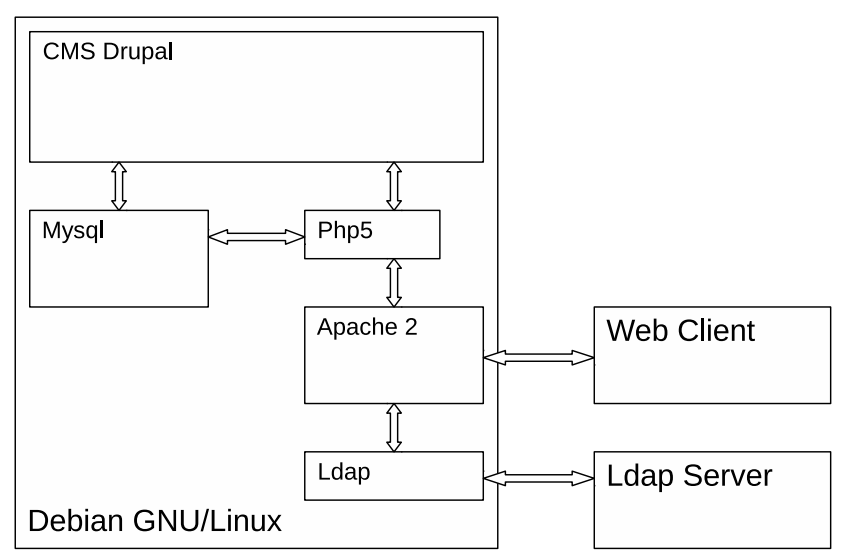

Fig. 1 Environment for implementation of program module

Nowadays a plethora of technologies are used for the presentation of various information on the web, e.g., hypertext language (HTML) [14] through PHP scripting [4, 5], together with MySQL database back-end [15]. To link the database and the website through PHP, we used the Drupal content management system, which enables flexible generating, editing, and management of websites, as well as adding multimedia content and setting access rights for users. See Fig. 1 for a graphical representation of the relations between the main modules of the application.

A user sends a client request using a web browser to the CMS website deployed on the Apache web server [23]. The server receives the request and handles it via PHP script of the corresponding CMS module. Furthermore, it uses PHP commands to connect to the MySQL database and queries for the content that belongs to the requested web page. The database then serves back the requested content, which is afterward displayed as the content on the CMS website.

\section{DATABASE DESIGN}

An important part of the application design process is an examination of ways to store information in a database. Our application is built with Drupal Content Management System [8], which offers only relational and embedded databases. For our work it is necessary that the database system supports the following characteristics:

- quick search of data,

- easy to work with the database,

- availability of data,

- simple modification using SQL commands,

- content management system (CMS) Drupal compatibility, and

- the database management system (DBMS) [11], the code of which is available under the terms of the GNU General Public License.

In addition to Drupal's compatible DBMS, we have examined the following ones: MySQL [15], Postgres [18], and SQLite [20]. Based on the above characteristics we have selected the Drupal's DBMS. In order to take advantage from the created database, it has to be linked with a website via client-server network architecture.

The life cycle of a database creation consists of several phases, such as setting goals, gathering requirements, database design, implementation, creating the prototype, filling the database, testing, service, and maintenance. It is important to create a database model, which consists of a conceptual, logical, and physical database model. The conceptual model shows the reality and relationships between data. It can be represented by a class diagram, showing relations and attributes of the classes, or by an entity relationship diagram, which describes database with entities, relations, and attributes [13].

We chose to represent the conceptual model (Fig. 6) with the entity relationship diagram, which we created using the Enterprise Architect [9] modeling tool. See Fig. 6 for the diagram (entities are depicted as rectangles and attributes as ellipses that are linked with each other).

Logical model is more specific and provides independence from specific database systems. We developed it in Toad Data Modeller [7] modeling tool that is used for design, development, and maintenance of database systems.

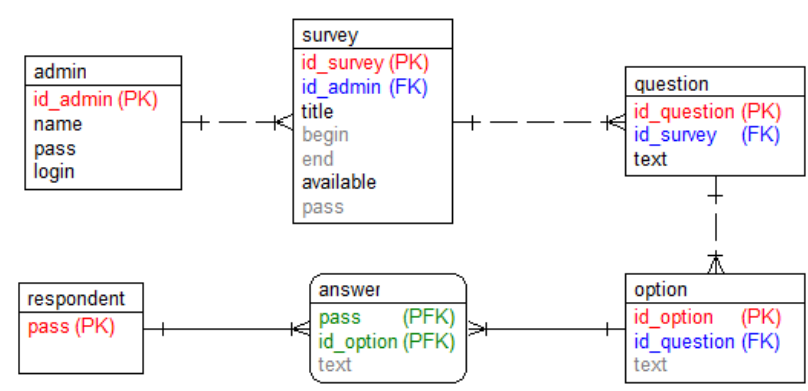

Fig. 2 Logical database model

Logical model in Fig. 2 shows entities as rectangles with name, attributes and relations as lines with the corresponding cardinality in the Information Engineering Notation. Here, a line ending with three little lines represents a "many", line ending with orthogonal little line represents "one", and a dashed line represents an optional relationship.

A physical database model describes the structure of the database data in more details, representing a realization of the system in a specific environment. To create the physical model of our application we used a Toad Data Modeller modeling tool, in which the target database system was set to MySQL. The physical model supports data types such as Integer, Varchar or Bool and restrictions as NN (Not $\mathrm{Nul1)}$, which disallows the empty value. See Fig. 3 for the graphical representation of the physical model of our application. 


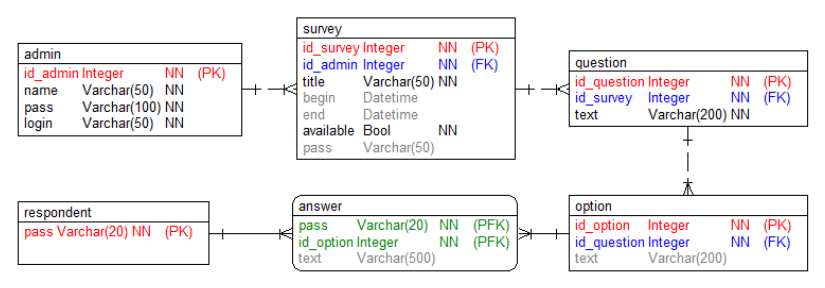

Fig. 3 Physical database model

\section{WEBSITE DESIGN}

The website has a certain structure and layout that depends on the topic and the required results. We propose that the website design should contain the following:

- After selecting a questionnaire bookmark, a text information for respondents will be displayed that contains the purpose of questionnaire surveys and short information about them. Furthermore, there will be information about the name of the course, which questionnaires belong to, and the name of each questionnaire, which are served by buttons.

- A page will be displayed asking for a valid password that a lecturer has set beforehand by clicking the questionnaire title.

- The questionnaire will be followed by a page after successful password verification, where a request to enter the identifier is shown. Each student should receive the identifier from the lecturer. The identifier will be randomly generated and is used only for grouping responses from the students. This page structure will be valid for access to each type of questionnaire. Pages for the specific questionnaires are different in their structure, and type of questions and answers.

- The information about questionnaire, concrete types of questions and responses, optional explanations for completing questionnaires will be displayed for each survey.

- The gratitude for sharing their opinions and thoughts will displayed to students after completing each questionnaire.

The following options are displayed to the teacher:

- login using his own credentials,

- showing answers from individuals or groups of students,

- filtering desired responses using various criteria, such as academic year, the lecturer and specific question,

- showing basic statistical measures obtained from the replies of students, and
- saving, reporting, and printing of obtained statistical values.

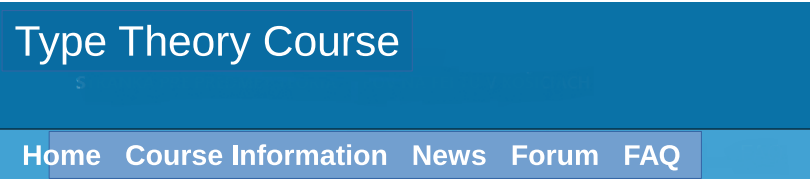

Fig. 4 Main menu for generic users

The main menu of the portal is designed for generic users (see Fig. 4), as well as authenticated users (see Fig. 5). The following menu selections are available for generic users:

- Course information comprised of basic information about the Type Theory course, for example study degree, study programme, field of study, semester, teaching form, assessment methods, credits, and teachers.

- News that consist of actual information about the course.

- Forum which serves as a electronic discussion web portal between students and teachers.

- FAQ (Frequently Asked Questions).

\section{Type Theory Course}

Home Course Information News Forum Lectures Exercises Materials Questionnaries FAQ

Fig. 5 Main menu for authenticated users

After the successful authentication, an extended menu is presented to the user. It consists of additional menu selections:

- Lectures, i.e., individual lectures that are presented by guarantee of the course in pdf file format,

- Exercises, that consists of electronic material related to proofs and evaluation of treated terms,

- Materials the actual electronic university textbooks, materials related to the course, and

- Questionnaires that includes Semantic differential, Cloze test and other surveys that are intended to improve the quality of educational process.

\section{QUESTIONNAIRES}

Anonymous questionnaires are "speechless interviews" between the teacher and students, intended to improve the teaching methods, as well as the essence of how a teacher can perform their own introspection and self-reflection from the pedagogical point of view.

The analysis of the proposed questionnaires is the basis for further work. It is necessary to know what questions 
should be included, whether they are suitable for what we want to find out, and whether they really help us to discover what we need. We considered the following types of questionnaires [10]:

- Semantic differential,

- Cloze test,

- questionnaire for evaluation of a teaching unit, and

- questionnaire to determine the quality of teaching.

Cloze test is a common empirical comprehension test used to measure how difficult a text is to be read and understood by respondent [1]. Semantic differential is a type of a rating-scale public inquiry, designed to measure the respondent attitudes to teacher's and student's characteristics. Questionnaire for evaluation of a teaching unit is an immediate student's feedback on the course, and questionnaire to determine the quality of teaching is a comprehensive view of a student on the course at the end of the semester.

We used the following mathematical formulæ to obtain veritable values:

Arithmetic mean of the sample calculated by means of

$$
\bar{x}=\frac{1}{n} \sum_{i=1}^{n} x_{i}
$$

where $x_{1}, x_{2}, \ldots, x_{n}$ are the field values and $n$ is the respondents count.

Standard deviation of the sample calculated as

$$
s=\sqrt{\frac{1}{n} \sum_{i=1}^{n}\left(x_{i}-\bar{x}\right)^{2}},
$$

where $\bar{x}$ is the concept average value, $x_{1}, x_{2}, \ldots, x_{n}$ are field values, and $n$ is the fields count.

In this paper we will deal in more detail Semantic differential questionnaire [22] for Type theory that consists of 14 pairs of properties. Each pair is evaluated by students on a scale of values from 1 to 7 , where value 1 is the worst evaluation and 7 is the best. See Table 1 for results of the questionnaire given to the class of 20 students during 2013/2014 academic year.

The characteristic properties in this table are divided into three dimensions:

1. antagonistic particular properties,

2. average values obtained at the beginning of the semester and
3. average values obtained at the end of the semester.

The students filled two questionnaires with the appropriate items. In the first one they gave their own opinion related to desired properties of the student. The other one is related to teacher's desired properties. The columns teacher and student represent results from these questionnaires. We have processed results from Table 1 into graphs depicted in Fig. 7 and Fig. 8 where the $x$-axis depicts treated properties and $x$-axis represents scale of the permissible values.

Based on the data obtained from the Semantic differential and our own observations, we get the following conclusions:

- The test results give feedback to the teacher's valued features, such as Acumen, gladness, relaxation, activity, etc.

- Deterioration occurs in the evaluation of predictability, where students at the end of the semester answered that teacher is more predictable, which can mean easier style of learning for students, but for the lecturer it does not have to have a positive impact on the course.

The evaluation of properties in Table 1 at the beginning of semester and at the end of the semester is not very different. Very small positive or negative changes in certain values suggest that the perception of the terms by students had not been changed significantly, and that the value of terms and properties is relatively positive.

\section{CONCLUSIONS}

In this work we have analyzed appropriate software development processes and methods for Type Theory courses questionnaire management system. We have chosen wellknown method, called Semantic differential, which uses subjective ratings of individual students.

Using this method we have examined changing students' perceptions of the teacher as well as other students over time (at the beginning and the end of the semester).

The results obtained from individual questionnaires collected exploratory information about chosen student's and teacher's properties. The collected data was statistically processed and evaluated. Based on that, we get the knowledge about the quality of teaching and a possibility how the teacher can obtain appropriate self-reflection.

For further improvement of the Type Theory course at the web, we would like to extend our approach in the future with the the possibility of developing a prototype that will be designed for courses taught at the Department of Social Sciences too, together with their cooperation. 


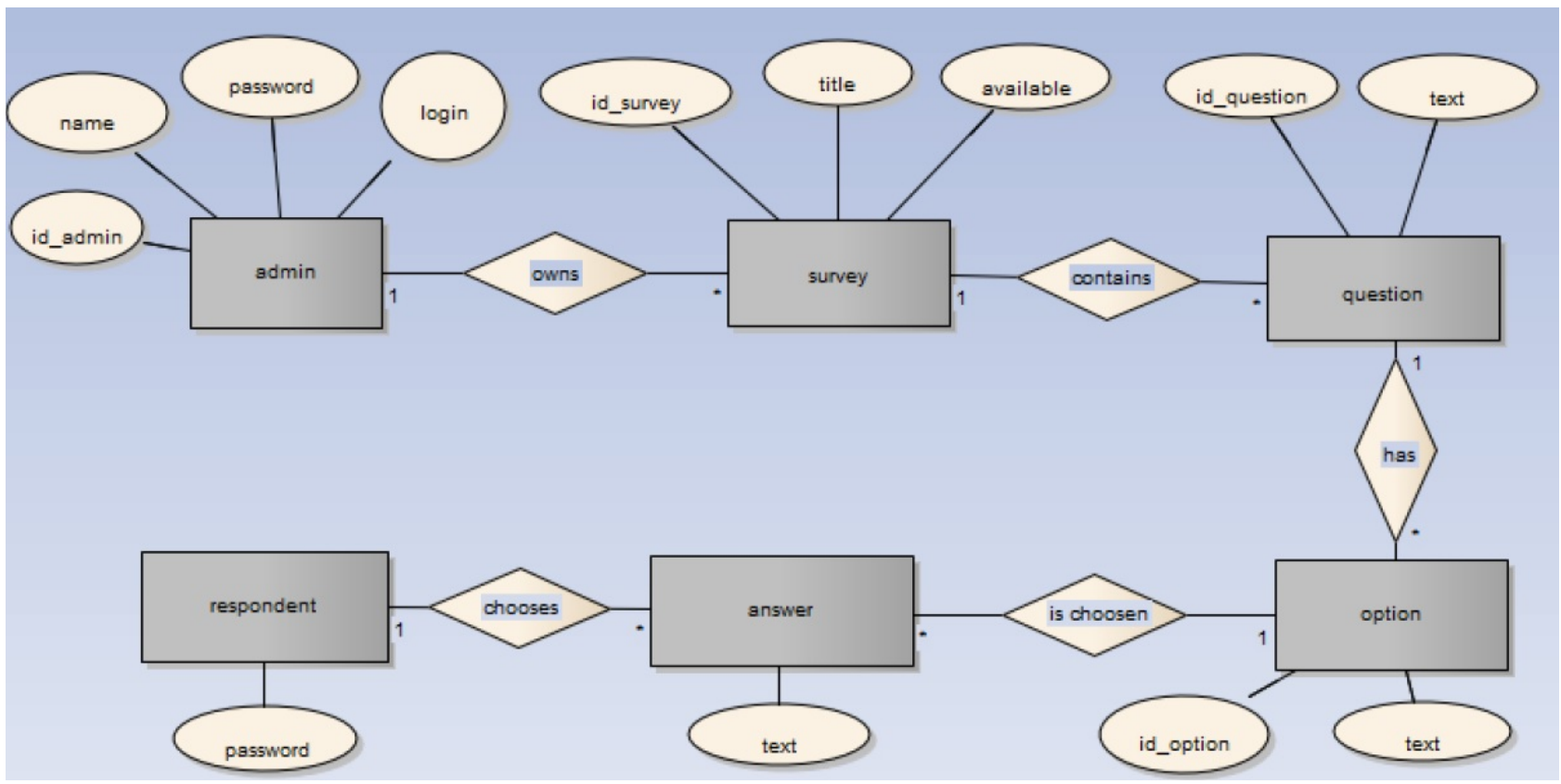

Fig. 6 Conceptual database model

Table 1 Comparison of average values of items before and after

\begin{tabular}{|c|c|c|c|c|c|}
\hline \multicolumn{2}{|c|}{ properties } & \multicolumn{2}{c|}{$\begin{array}{c}\text { average values } \\
\text { before }\end{array}$} & \multicolumn{2}{c|}{$\begin{array}{c}\text { average values } \\
\text { after }\end{array}$} \\
\hline 1 & 7 & teacher & student & teacher & student \\
\hline bad & good & 6.2 & 6.05 & 5.9 & 5.3 \\
\hline worthless & valuable & 6.15 & 5.65 & 6.05 & 5.65 \\
\hline unknown & familiar & 5.05 & 4.45 & 5.2 & 4.5 \\
\hline stupid & smart & 6.55 & 6.5 & 6.4 & 6.2 \\
\hline dangerous & safe & 5.6 & 6.1 & 5.15 & 5.65 \\
\hline sad & happy & 6.5 & 6.2 & 5.45 & 5.6 \\
\hline distant & close & 5.25 & 4.7 & 5.05 & 4.9 \\
\hline predictable & unpredictable & 4.9 & 3.6 & 3.7 & 3.2 \\
\hline tense & relaxed & 6.25 & 5.75 & 5.8 & 5.55 \\
\hline repellent & attractive & 5.15 & 5.15 & 4.8 & 4.75 \\
\hline cheeky & polite & 5.8 & 6.2 & 5.75 & 5.5 \\
\hline passive & active & 6.5 & 5.95 & 6.1 & $\mathbf{6 . 0 5}$ \\
\hline weak & strong & 5.45 & 5.3 & 5.25 & 5.05 \\
\hline unpleasant & kind & 6.5 & 6.25 & 6.2 & 5.8 \\
\hline
\end{tabular}




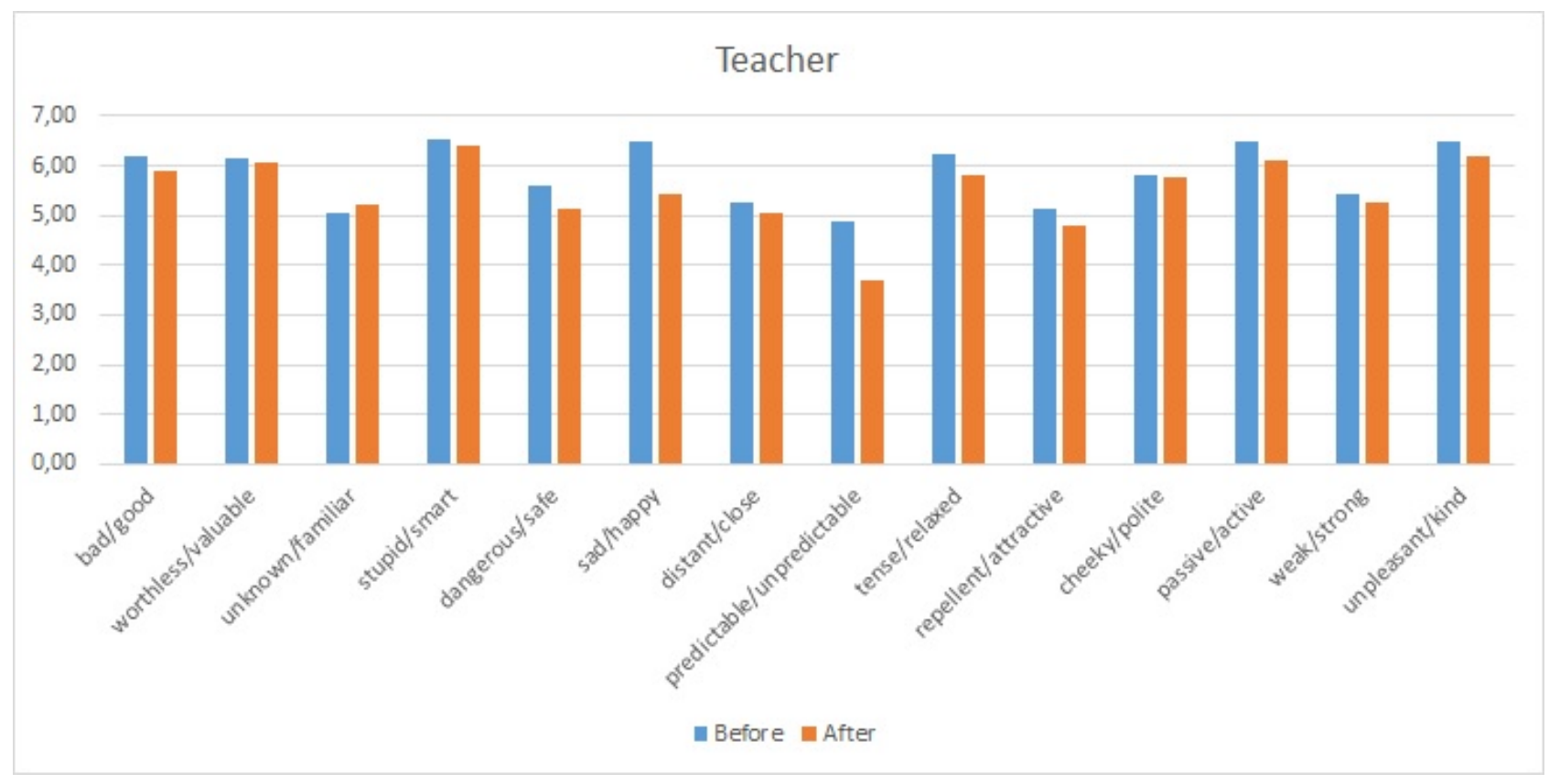

Fig. 7 Semantic diferential results for a teacher

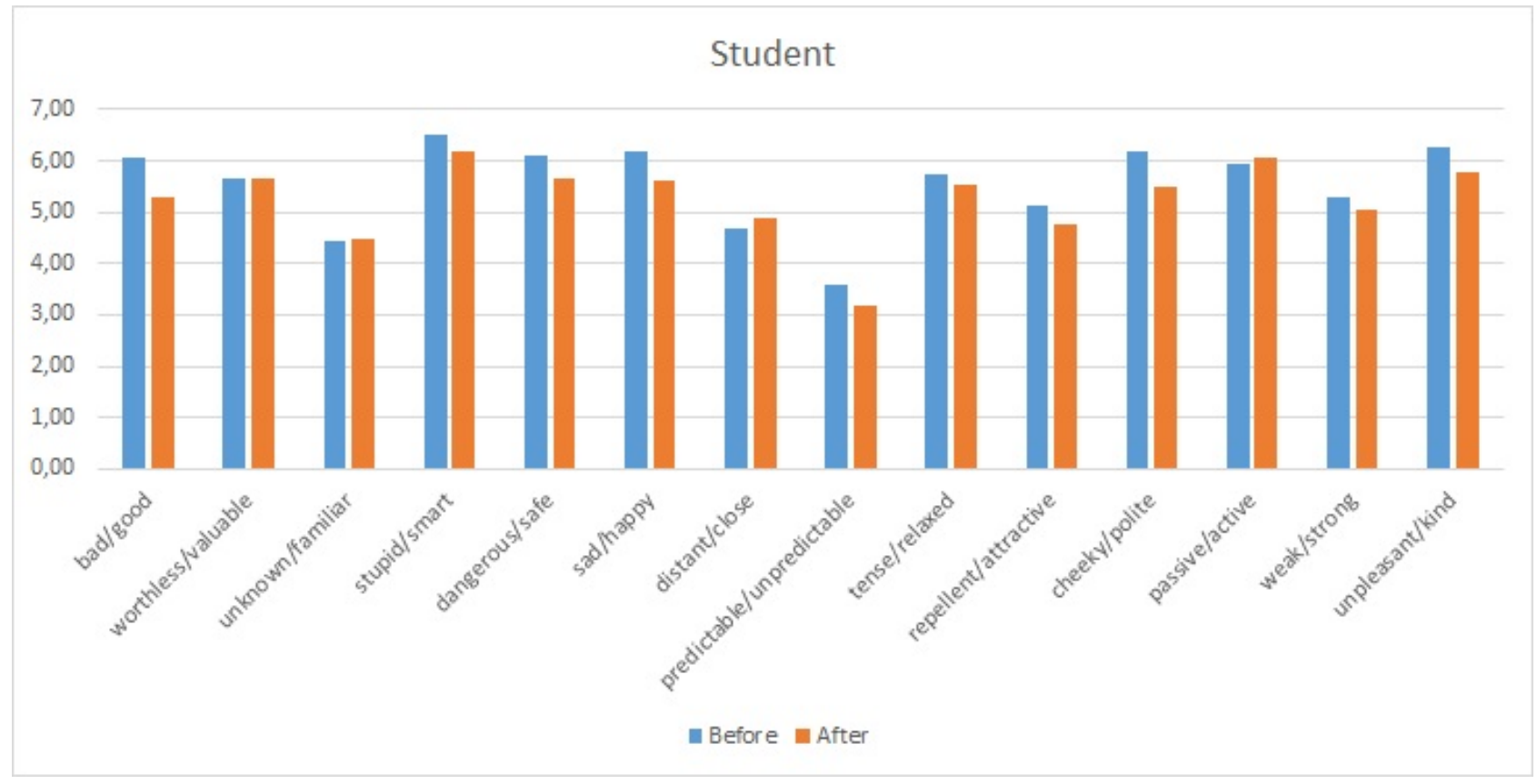

Fig. 8 Semantic diferential results for a student

\section{ACKNOWLEDGEMENT}

This work was partially supported by the Slovenian Research Agency and the projects "P2-0095 Parallel and distributed systems" and "N2-0053 Graph Optimisation and Big Data.

This work was supported by KEGA project ViLMA: Virtual Laboratory for Malware Analysis (079TUKE04/2017).
This work is a result of international cooperation under the CEEPUS network No.CIII-HU-0019-12-1617.

\section{REFERENCES}

[1] BAJTOŠ, J.: Didaktika vysokej školy, Wolters Kluwer (Iura Edition), pp. 400, 2016, ISBN 9788080786526.

[2] BENEJ, M. - ŠIMOŇÁK, S.: Algomaster platform 
extension for improved usability, In: Journal of Electrical and Electronics Engineering, Vol. 10, No. 1, 2017, pp. 27-30, ISSN 1844-6035.

[3] BLAŠKO, M.: Planning and realization of educational activity in teaching system with a closed PDCA cycle, Department of Engineering Education, Technical University of Košice, 2014, http://web.tuke.sk/ kip/download/vucP9E.pptx

[4] CASTANETTO, J. - RAWAT, H. - SCHUMANN, S. - SCOLLO, Ch. - WELIATH, D.: Programujeme PHP profesionálně, Computer press, Praha, 2002.

[5] COWBURN, P.: PHP Manual Copyright (C)2016, The PHP Group., https://secure.php.net/

[6] Debian: Debian installation manua Copyright (c)2004 2015, https://www.debian.org/releases/stable/ i386/

[7] Dell ${ }^{T M}$ : $\operatorname{Toad}^{T M}$ Data Modeler Copyright (C)2016, Dell Inc., http://software.dell.com/products/ toad-data-modeler/

[8] Drupal: Drupal 7 - online documentation Copyright (C) 2016, https://www.drupal.org/docs/7

[9] SPARX SYSTEMS Enterprise Architect Copyright (C) 2017, http://www. sparxsystems.com .au/

[10] GAVORA, P. at al.: Elektronická učebnica pedagogického výskumu Bratislava, Univerzita Komenského, 2010, ISBN 9788022329514, http://www.e-metodologia.fedu.uniba.sk/

[11] GRAY, J.: Database Modeling \& Design, Fourth Edition, Morgan Kaufmann Publishers, (C)2006 by Elsevier Inc. All rights reserved, 2006, ISBN 10: 0-12685352-5.

[12] JACKOWSKA-STRUMILLO, L. - NOWAKOWSKI, J. - STRUMILLO, P. - TOMCZAK, P.: Interactive Question Based Learning Methodology and Clickers: Fundamentals of Computer Science Course Case Study, IEEE International Conference on Human System Interactions, pp. 439-442, 2013, ISSN 22177930.

[13] MALLIG, N.: A relational database for bibliometric analysis, Fraunhofer ISI Discussion Papers Innovation Systems and Policy Analysis, No. 22, Fraunhofer Institute for Systems and Innovation Research, Karlsruhe, 2010, ISSN 1612-1430 http://www.isi.fraunhofer.de/isi-wAssets/ docs/p/de/diskpap_innosysteme_policyanalysel /discussionpaper_22_2010.pdf

[14] MDN Contributors: HTML. Mozilla Developer Network., 2016, https://developer.mozilla.org/ en-US/docs/Web/HTML

[15] Oracle ${ }^{T M}: \mathrm{MySQL}^{T M}$ Reference Manual Copyright (c) 2016, Oracle and/or its affiliates, 2016, http:// downloads.mysql.com/docs/refman-5.7-en.pdf

[16] PENIAŠKOVÁ, M. - MIHÁLYI, D.: Educational Documentation Methods for Improving the Quality of Course Education and Teacher Selfreflection: Electrical Engineering and Informatics 7, Proceedings of the
Faculty of Electrical Engineering and Informatics of the Technical University of Košice, Košice: FEI TU, pp. 140-145, 2016, ISBN 978-80-553-2599-6.

[17] PIETRIKOVÁ, E.: Audience Response Systems: Benefits \& Utilization, In: Acta Electrotechnica et Informatica, Vol. 15, No. 4, pp. 3-7, 2015, ISSN 1338395

[18] Postgres: PostgreSQL 9.6.2 Documentation, Copyright (C)2016, The PostgreSQL Global Development Group, https://www.postgresql.org/files/ documentation/pdf/9.6/postgresql-9.6-A4.pdf

[19] ROŽANC, I. - MIHELIČ, J.: Evaluating the effect of the automatic assessment introduction in the ADS1 course practical work. Proceedings of MIPRO 2015 38th International Convention, Opatija, Croatia, 2015, pp. 879-884, ISSN 1847-3946.

[20] SQLite: SQLite documentation, Copyright (c)2016, The SQLite Consortium, https://www.sqlite.org/ 2017/sqlite-doc-3170000.zip

[21] TKÁČOVÁ, R. - STEINGARTNER, W.: Use of information and communication technologies in business and households in context of the digital economy, In: Knowledge for Market Use 2017, Olomouc, Palack University, pp. 600-605, 2017, ISBN 978-80244-5233-3.

[22] WHITNEY, G. - SOUKUP, W.: A semantic Differential Instrument to Evaluate Experimental Teaching Methods, Developments in Business Simulation \& Experiential Exercises, Vol. 15, 1988.

[23] YANK, K.: Build Your Own Database Driven Website Using PHP \& MySQL: Pt. 4. Birkhäuser Boston, 2002.

Received August 20, 2017, accepted October 5, 2017

\section{BIOGRAPHIES}

Daniel Mihályi has worked as a researcher at the Department of Computers and Informatics of the Faculty of Electrical Engineering and Informatics at Technical University of Košice and later as Assistant Professor. In 2009 he defended PhD. thesis "Duality Between Formal Description of Program Construction and Program Behaviour". In 2015 he graduated as International Engineering Educator in accordance to accreditation criteria defined by the IGIP organisation. The main area of his pedagogical research includes master elearning, IT4KT and security of web information systems.

Monika Peniašková was born in 1992 in Slovakia. In 2016 she graduated (MSc) at the Department of Computers and Informatics of the Faculty of Electrical Engineering and Informatics at Technical University of Košice. She defended her master's thesis in the field of Informatics. She is concerned with design of information systems and questionnaires analysis. 
Ján Perháč was born in 1991 in Svidník, Slovakia. In 2015 he graduated (MSc) at the Department of Computers and Informatics of the Faculty of Electrical Engineering and Informatics at Technical University of Košice. He defended his master's thesis in the field of Informatics. He is concerned with GNU/Linux operating systems, network security, non-traditional logical systems and category theory.
Jurij Mihelič received his doctoral degree in Computer Science from the University of Ljubljana in 2006. Currently, he is with the Laboratory of Algorithms and Data Structures, Faculty of Computer and Information Science, University of Ljubljana, Slovenia, as an assistant professor. His research interests include algorithm engineering, combinatorial optimization, and system software. 